Jurnal Keperawatan Silampari

Volume 4, Nomor 2, Juni 2021

e-ISSN: 2581-1975

p-ISSN: 2597-7482

DOI: https://doi.org/10.31539/jks.v4i2.1942

\title{
INTERVENSI HEALTH COACHING DALAM MENINGKATKAN PENGETAHUAN DAN SIKAP PENCEGAHAN PENULARAN TUBERKULOSIS
}

\author{
Evi Supriatun ${ }^{1}$, Uswatun Insani ${ }^{2}$ \\ Sekolah Tinggi Ilmu Kesehatan Bhakti Mandala Husada Slawi ${ }^{1,2}$ \\ evisupriatun@gmail.com ${ }^{1}$
}

\begin{abstract}
ABSTRAK
Penelitian ini bertujuan untuk mengetahui pengaruh health coaching terhadap pengetahuan dan sikap tentang pencegahan penularan tuberkulosis pada pasien yang masih menjalani pengobatan tuberkulosis rutin di Kabupaten Tegal. Desain penelitian yang digunakan adalah quasi experiment dengan pre and post test with control grup. Hasil analisis bivariat diketahui bahwa pada kelompok intervensi yang telah diberikan health coaching selama 4 (empat) sesi, berpengaruh secara bermakna pada pengetahuan dan sikap responden dibandingkan dengan kelompok kontrol yang tidak diberikan health coaching. Hal tersebut dapat diketahui dari adanya perbedaan nilai sebelum dan sesudah diberikan perlakuan health coaching pada kelompok intervensi. Selain itu, hasil analisis bivariate dengan menggunakan independent $t$ test menunjukkan p-value $0,000<0,05$. Simpulan, terdapat pengaruh penerapan health coaching terhadap pengetahuan dan sikap tentang pencegahan penularan penyakit tuberkulosis pada pasien tuberkulosis di Kabupaten Tegal.
\end{abstract}

Kata Kunci: Health Coaching, Pencegahan Penularan Tuberkulosis, Pengetahuan, Sikap

\begin{abstract}
This study aims to determine the effect of health coaching on knowledge and attitudes about the prevention of tuberculosis transmission in patients who are still undergoing routine tuberculosis treatment in Tegal Regency. The research design used was a quasiexperiment with pre and post-test with the control group. The results of the bivariate analysis showed that in the intervention group that had been given health coaching for 4 (four) sessions, it had a significant effect on the knowledge and attitudes of the respondents compared to the control group that was not given health coaching. This can be seen from the difference in values before and after being given health coaching treatment in the intervention group. Also, the results of the bivariate analysis using the independent $t$-test showed a p-value of $0.000<0.05$. In conclusion, there is an effect of the implementation of health coaching on knowledge and attitudes about the prevention of transmission of tuberculosis in tuberculosis patients in Tegal Regency.
\end{abstract}

Keywords: Health Coaching, Prevention of Tuberculosis Transmission, Knowledge, Attitude 


\section{PENDAHULUAN}

Tuberkulosis merupakan penyakit infeksi menular pada paru-paru yang dapat menyebabkan kematian, infeksi ini disebabkan oleh mycobacterium tuberculosis dan masih menjadi salah satu masalah kesehatan di dunia (Ali et al., 2019; Gloria et al., 2019). Kejadian penyakit tuberkulosis juga terjadi secara global di dunia dengan jumlah angka kesakitan yang masih tinggi (Peña et al., 2018). Meskipun angka kematian penyakit tuberkulosis telah menurun dibandingkan dengan tahun sebelumnya, namun angka kejadian penyakit tuberkulosis masih menjadi penyebab kematian nomor satu di antara penyakit menular lainnya yang terjadi pada orang yang berusia lebih dari 5 (lima) tahun (Holden et al., 2020). Peningkatan angka kesakitan dan angka kematian penyakit tuberkulosis memerlukan upaya pencegahan dengan memperhatikan faktor-faktor yang menyebabkan cepatnya penularan tuberkulosis di masyarakat (Reid et al., 2019).

Peningkatan kasus tuberkulosis secara global telah banyak menginfeksi penduduk di berbagai negara. Berdasarkan data dari Global Tuberculosis Report 2019 menyatakan bahwa kasus tuberkulosis terbanyak pada tahun 2018 terdapat di wilayah Asia Tenggara (44\%), Afrika (24\%) dan Pasifik Barat (18\%) dengan bagian yang lebih kecil di wilayah Timur Mediterania (8\%), Amerika (3\%) dan Eropa (3\%). Prevalensi tuberkulosis di Indonesia juga sangat tinggi, dimana kasus tuberkulosis di Indonesia termasuk dalam negara penyumbang kasus tuberkulosis terbanyak ketiga sebesar 8\% dari total keseluruhan kasus di dunia, setelah negara India (27\%) dan China (9\%) (WHO, 2019).

Langkah awal upaya penanganan tuberkulosis dilakukan dengan menemukan kasus baru tuberkulosis dan dilanjutkan dengan pengobatan secara rutin. Angka case notification rate tuberkulosis di Indonesia terbanyak berada di Provinsi DKI Jakarta (393/100.000 penduduk), Papua (355/100.000 penduduk) dan Gorontalo (338/100.000 penduduk) (Kementrian Kesehatan RI, 2019). Tingginya case notification rate di berbagai wilayah yang berbeda-beda disebabkan adanya perbedaan keadaan geografi dari masing-masing wilayah yang secara tidak langsung berpengaruh terhadap penanggulanagan tuberkulosis (Parwati et al., 2020).

Faktor non fisik yang menjadi penyebab tersering mudahnya penularan tuberkulosis yaitu kurangnya motivasi dan ketidakpatuhan pengobatan tuberkulosis secara berkelanjutan dimana pasien mengalami putus obat dan tidak memanfaatkan pelayanan kesehatan untuk berkonsultasi ke petugas pelayanan kesehatan (Mamahit et al., 2019). Faktor lainnya adalah kurangnya pengetahuan panduan berobat tuberkulosis (Andri et al., 2020; Gloria et al., 2019).

Kurangnya pemahaman terkait penyakit tuberkulosis mendasari penyebab utama penanganan tuberkulosis tidak dapat berjalan dengan optimal (Putri et al., 2020). Hal ini memperberat kondisi sosial ekonomi masyarakat yang sebagian besar pasien mengalami kesulitan ekonomi dalam perawatan pasien tuberkulosis (Ncube, 2018). Pasien yang terdiagnosa tuberkulosis masih ada yang belum memiliki pemahaman bahwa tuberkulosis dapat menular. Hal tersebut mengakibatkan pasien tuberkulosis tidak dapat mematuhi aturan pengobatan tuberkulosis dengan tepat dan melaksanakan upaya pencegahan penularan dalam perilaku sehari-harinya (Salame et al., 2017).

Dampak yang terjadi akibat kurangnya kesadaran pencegahan penularan penyakit tuberkulosis secara tidak langsung menjadi penyebab utama meningkatkan angka kesakitan penyakit tuberkulosis. Hal tersebut dikarenakan pasien tuberkulosis yang tidak menerapkan prinsip pencegahan penularan penyakit tuberkulosis justru menjadi sumber infeksi mycobacterium tuberculosis di lingkungan sekitarnya sehingga keluarga, teman ataupun tetangga (Dumpeti et al., 2020). 
Peningkatan kasus tuberkulosis yang semakin meningkat memerlukan upaya penanganan dan pengorganisasian yang tepat agar penemuan kasus tuberkulosis dapat dilakukan tindak lanjut secara tepat (Inayah \& Wahyono, 2019). Stategi penanganan tuberkulosis dimulai dari langkah penemuan kasus selanjutnya pasien yang disarankan untuk melakukan pengobatan tuberkulosis secara tepat. Upaya penanganan yang dilakukan dengan strategi Directly Observed Treatment Short Course Therapy(DOTS) telah dilakukan sebagai langkah utama pengendalian tuberkulosis (Kim et al., 2020). Selain itu, berbagai upaya edukasi kesehatan yang diberikan pada pasien tuberkulosis juga telah diberikan namun tindakan pencegahan penularan tuberkulosis masih belum optimal. Penanganan tuberkulosis sangat diperlukan agar pasien tuberkulosis yang terdiagnosis dapat berkomitmen dalam pengobatan sampai dengan selesai (Pratama et al., 2018).

Pasien tuberkulosis yang terdiagnosis tuberkulosis sebagian besar hanya berfokus pada prosedur pengobatan yang dijalankan, sementara dalam hal pencegahan masih kurang diperhatikan. Prosedur pengobatan yang cukup lama dan harus rutin menjadi perhatian pasien tuberkulosis agar mampu mencapai target tersebut. Padahal pemahaman terhadap bahaya penyakit tuberkulosis yang dapat menular juga perlu dipahami oleh pasien tuberkulosis (Kwon \& Choi, 2020). Hal tersebut memerlukan dukungan dari petugas kesehatan pada pasien tuberkulosis dan keluarga sehingga memiliki inisiatif dan antusiasme dalam memahami kebiasaan yang dapat menjadi sumber infeksi tuberkulosis dan upaya yang dapat dilakukan keluarga untuk mencegah mycobacterium tuberculosis dapat hidup di tempat tinggal pasien dan keluarga (Bojovic et al., 2018).

Pasien tuberkulosis memiliki pemahaman pencegahan tuberkulosis yang didapatkan dari berbagai macam sumber informasi. Sebagian besar pasien tuberkulosis mendapatkan informasi pencegahan penularan tuberkulosis dari petugas kesehatan yang memberikan arahan program pengobatan tuberkulosis. Sementara sebagian yang lainnya memperoleh informasi dengan cara melakukan pencarian informasi secara mandiri melalui sumber penelusuran internet atau referensi buku. Pasien tuberkulosis membutuhkan dukungan dari petugas kesehatan untuk selalu membimbing dalam berbagai upaya pencegahan dan pengobatan dalam jangka waktu yang cukup lama (Charyeva et al., 2019).

Health coaching merupakan salah satu intervensi keperawatan dengan strategi berupa pendampingan pada pasien memberikan kesempatan pada pasien untuk menentukan hal yang ingin dicapai dan menentukan solusi untuk mencapai tujuan dalam program pengobatan yang sedang dijalaninya (Singh et al., 2020). Pasien tuberkulosis membutuhkan pendampingan dalam memahami program terapi yang dijalaninya. Hal ini dikarenakan pasien masih belum memahami bahaya tuberkulosis dan cara melakukan pengobatan dengan rutin serta cara agar menularkan pada orang lain (Widiyanto, 2017). Penerapan coaching dapat dilakukan perawat untuk membantu pasien tuberkulosis selama masa pengobatan. Pasien tuberkulosis dapat mengidentifikasi hal-hal yang dibutuhkannya, diantaranya pemahaman penyakit tuberkulosis, pencegahan yang dapat dilakukan dan pemanfaatan pelayanan kesehatan yang tepat (Chelagat et al., 2020).

Beberapa penelitian sebelumnya pernah dilakukan untuk meningkatkan pengetahuan dan sikap pencegahan tuberkulosis, namun pada penelitian ini berfokus pada intervensi health coahing dengan cara pendampingan pada pasien. 


\section{METODE PENELITIAN}

Penelitian ini menggunakan desain kuantitaf dengan desain quasi experimental pre post test with control group. Intervensi pada penelitian ini berfokus pada pemberian informasi dan bimbingan kesehatan terkait pencegahan penularan penyakit tuberkulosis. Penelitian ini dilakukan di Wilayah Kerja Puskesmas Kabupaten Tegal. Untuk penentuan lokasi penelitian ini menyesuaikan dengan teknik cluster sampling yang menentukan wilayah kelompok intervensi, kontrol dan lokasi uji validitas dan reliabiltas berdasarkan prevalensi penyakit tuberkulosis. Untuk uji validitas dan reliabilitas dilakukan di Puskesmas Pagiyanten. Kelompok kontrol merupakan pasien tuberkulosis dari Puskesmas Talang dan Kelompok intervensi diambil dari Puskesmas Dukuhturi dan Kaladawa Kabupaten Tegal.

Pengambilan sampel pada penelitian ini menggunakan random sampling dengan kriteria inklusi yaitu pasien berusia 17 sampai 59 tahun, pasien tuberkulosis paru yang terdiagnosis BTA positif, menjalani pengobatan tuberkulosis kurang dari 5 bulan, tidak mengalami gangguan dalam berbicara atau pendengaran, tinggal di wilayah Kabupaten Tegal. Adapun kriteria eksklusinya yaitu pasien dengan komplikasi penyakit HIV/AIDS atau terklasifikasi pada TB-MDR. Jumlah sampel pada penelitian ini ditentukan dengan menggunakan rumus beda mean berpasangan. Berdasarkan penghitungan sampel tersebut, maka sampel yang dibutuhkan pada kelompok intervensi sebanyak 34 responden dan pada kelompok kontrol sebanyak 34 responden, sehingga jumlah total sebanyak 68 responden.

Peneliti memberikan perlakuan berupa health coaching tentang pencegahan penularan penyakit tuberkulosis selama 4 sesi pertemuan dengan durasi 30 sampai 60 menit. Ketika peneliti memberikan edukasi dan mengajarkan keterampilan pencegahan penularan penyakit tuberkulosis, pasien dan keluarga dapat bertanya dan menyampaikan kendala atau hambatan pada peneliti sehingga dapat disesuaikan dengan pasien tuberkulosis dan keluarga

\section{HASIL PENELITIAN}

Tabel. 1

Distribusi Karakteristik Responden Berdasarkan Jenis Kelamin dan Tingkat Pendidikan $(\mathrm{n}=68)$

\begin{tabular}{llcccc}
\hline \multirow{2}{*}{ Karakteristik Responden } & \multicolumn{2}{c}{ Intervensi } & \multicolumn{2}{c}{ Kontrol } \\
\cline { 2 - 5 } & $\mathrm{n}(34)$ & $\%$ & $\mathrm{n}(34)$ & $\%$ \\
\hline Jenis Kelamin & & & & \\
1. & Laki - Laki & 15 & 44,1 & 19 & 55,9 \\
2. & Perempuan & 19 & 55,9 & 15 & 44,1 \\
\hline \multicolumn{2}{c}{ Tingkat Pendidikan } & & & & \\
0. & Tidak Sekolah & 3 & 8,8 & 3 & 8,8 \\
1. & SD & 24 & 70,6 & 17 & 50,0 \\
2. & SLTP & 3 & 8,8 & 6 & 17,6 \\
3. & SLTA & 3 & 8,8 & 8 & 23,5 \\
4. & Perguruan Tinggi & 1 & 2,9 & 0 & 0 \\
\hline
\end{tabular}

Berdasarkan tabel 1 menunjukkan bahwa pada kelompok intervensi mayoritas berjenis kelamin perempuan yaitu sebanyak $19(55,9 \%)$ responden. Sedangkan pada kelompok kontrol mayoritas berjenis kelamin laki-laki yaitu sebanyak $19(55,9 \%)$ responden. Adapun untuk karakteristik tingkat pendidikan responden menunjukkan 
sebagian besar memiliki pendidikan tingkat Sekolah Dasar (SD) yaitu pada kelompok intervensi sebesar 70,6\% sedangkan pada kelompok kontrol sebesar 50\%.

Tabel. 2

Distribusi Rerata Pengetahuan Responden tentang Pencegahan Penularan Tuberkulosis $(n=68)$

\begin{tabular}{lllll}
\hline \multicolumn{1}{c}{ Pengetahuan } & \multicolumn{1}{c}{ Kelompok } & $\mathrm{n}$ & Mean & SD \\
\hline \multirow{2}{*}{ Sebelum } & Intervensi & 34 & 37,24 & 6,620 \\
\cline { 2 - 5 } & Kontrol & 34 & 42,44 & 3,711 \\
\hline \multirow{2}{*}{ Sesudah } & Intervensi & 34 & 49,71 & 4,877 \\
\cline { 2 - 5 } & Kontrol & 34 & 44,38 & 3,482 \\
\hline
\end{tabular}

Berdasarkan tabel 2 menunjukkan bahwa rerata pengetahuan sebelum pemberian perlakuan health coaching pada kelompok intervensi lebih rendah dibandingkan dengan kelompok kontrol dengan nilai rata-rata pada kelompok intervensi 37,24 dan SD 6,620, sedangkan pada kelompok kontrol rata-rata 42,44 dan SD 3,711. Rerata pengetahuan setelah pemberian perlakuan health coaching pada kelompok intervensi lebih tinggi dibandingkan dengan kelompok kontrol dengan nilai rata-rata pada kelompok intervensi 49,71 dan SD 4,877, sedangkan pada kelompok kontrol rata-rata 44,38 dan SD 3,482.

Tabel. 3

Distribusi Rerata Sikap Responden tentang Pencegahan Penularan Tuberkulosis $(n=68)$

\begin{tabular}{lllll}
\hline \multicolumn{1}{c}{ Sikap } & \multicolumn{1}{c}{ Kelompok } & $\mathrm{n}$ & Mean & SD \\
\hline \multirow{2}{*}{ Sebelum } & Intervensi & 34 & 40,53 & 4,507 \\
\cline { 2 - 5 } & Kontrol & 34 & 43,38 & 3,924 \\
\hline \multirow{2}{*}{ Sesudah } & Intervensi & 34 & 51,94 & 2,616 \\
\cline { 2 - 5 } & Kontrol & 34 & 45,74 & 4,433 \\
\hline
\end{tabular}

Berdasarkan tabel 3 menunjukkan rerata sikap sebelum intervensi tentang pencegahan penularan tuberkulosis pada kelompok kontrol lebih tinggi dibandingkan dengan kelompok intervensi yaitu dengan rerata kelompok intervensi 40,35 dan SD 4,507, sedangkan kelompok kontrol rata-rata 43,38 dan SD 3,924. Rerata sikap sesudah intervensi tentang pencegahan penularan tuberkulosis pada kelompok kontrol lebih rendah dibandingkan dengan kelompok intervensi yaitu dengan rata-rata kelompok intervensi 51,94 dan SD 2,616, sedangkan kelompok kontrol rata-rata 45,74 dan SD 4,433 .

Tabel. 4

Analisis Perubahan Skor Pengetahuan dan Sikap Sebelum dan Sesudah Perlakuan pada Kelompok Intervensi dan Kontrol ( $\mathrm{n}=68)$

\begin{tabular}{|c|c|c|c|c|c|c|c|c|}
\hline \multirow{3}{*}{ Variabel } & \multicolumn{4}{|c|}{ Kelompok Intervensi } & \multicolumn{4}{|c|}{ Kelompok Kontrol } \\
\hline & Sebelum & Sesudah & & & Sebelum & Sesudah & & \\
\hline & $\begin{array}{c}\text { Mean } \\
(\mathrm{SD})\end{array}$ & $\begin{array}{c}\text { Mean } \\
(\mathrm{SD})\end{array}$ & Selisih & $p$ value & $\begin{array}{c}\text { Mean } \\
(\mathrm{SD})\end{array}$ & $\begin{array}{c}\text { Mean } \\
(\mathrm{SD})\end{array}$ & Selisih & $p$ value \\
\hline Pengetahuan & $\begin{array}{c}37,24 \\
(6,620)\end{array}$ & $\begin{array}{c}49,71 \\
(4,877)\end{array}$ & 12,47 & 0,000 & $\begin{array}{c}42,44 \\
(3,711)\end{array}$ & $\begin{array}{c}44,38 \\
(3,482)\end{array}$ & 1,94 & 0,000 \\
\hline Sikap & $\begin{array}{c}40,53 \\
(4,507)\end{array}$ & $\begin{array}{c}51,94 \\
(2,616)\end{array}$ & 11,41 & 0,000 & $\begin{array}{c}43,38 \\
(3,924)\end{array}$ & $\begin{array}{c}46,74 \\
(4,433)\end{array}$ & 2,35 & 0,000 \\
\hline
\end{tabular}


Berdasarkan tabel 4 menunjukkan bahwa perubahan rerata skor pengetahuan pada kelompok intervensi dari sebelum dan setelah diberikan perlakuan health coaching, menunjukkan peningkatan rerata skor pengetahuan 12,47. Rerata skor pengetahuan pencegahan penularan penyakit tuberkulosis tersebut lebih besar dibandingkan dengan kelompok kontrol. Health coaching yang diterapkan pada kelompok intervensi, dengan memberikan bimbingan secara bertahap memberikan pemahaman pada responden kelompok intervensi sehingga skor pengetahuan pencegahan tuberkulosis meningkat. Untuk perubahan rerata skor sikap pada responden penelitan pada kelompok kontrol tidak menunjukkan peningkatan yang besar jika dibandingkan dengan kelompok intervensi.

Tabel. 5

Analisis Perbedaan Pengetahuan dan Sikap Responden antara Kelompok Intervensi dan Kontrol $(n=68)$

\begin{tabular}{lccccc}
\hline \multirow{2}{*}{ Variabel } & \multicolumn{3}{c}{ Intervensi } & \multicolumn{3}{c}{ Kontrol } & \multirow{2}{*}{ p value } \\
\cline { 2 - 5 } & Mean & SD & Mean & SD & \\
\hline Pengetahuan & 49,71 & 0,816 & 44,38 & 3,482 & $0,000^{*}$ \\
\hline Sikap & 51,94 & 2,616 & 46,74 & 4,433 & $0,000^{*}$ \\
\hline
\end{tabular}

Berdasarkan tabel 5 menunjukkan adanya pengaruh health coaching terhadap pengetahuan responden pada kelompok intervensi dengan nilai p 0,000. Variabel sikap juga menunjukkan signifikansi, dimana skor rerata sikap pada kelompok intervensi meningkat setelah diberikan perlakuan health coaching dengan nilai p 0,000 .

\section{PEMBAHASAN}

Karakteristik responden penelitian ini berjumlah 68 orang dengan perbandingan jenis kelamin laki-laki dan perempuan yang hampir sama. Hal tersebut menunjukkan bahwa terdapat beberapa faktor yang menyebabkan laki-laki maupun perempuan memiliki resiko tertular penyakit tuberkulosis. Secara spesifik yang terjadi pada kelompok intervensi, hasil penelitian mendeskripsikan responden berjenis kelamin perempuan lebih banyak yang mengalami tuberkulosis dibandingkan laki-laki. Hal tersebut sejalan dengan penelitian yang dilakukan oleh Saunders et al., (2019) yang menjelaskan perempuan lebih berisiko mengalami tuberkulosis karena sebagian besar perempuan ketika terpapar tuberkulosis tidak terdeteksi secara diagnostik kepada pelayanan kesehatan terdekat untuk menyampaikan tanda dan gejala yang dirasakannya. Hal tersebut menyebabkan penanganan penyakit tuberkulosis yang kurang cepat dan beratnya keluhan yang dirasakan klien serta penularan pada orang di sekitarnya. Penelitian yang dilakukan oleh (Smiljić et al., 2019) juga menunjukkan tuberkulosis lebih banyak dialami oleh responden perempuan. Hal tersebut disebabkan oleh kondisi yang terbiasa terpapar oleh asap rokok dan tidak menerapkan upaya pencegahan tuberkulosis dalam kebiasaan sehari-hari.

Tingkat pendidikan menjadi salah satu faktor yang dianalisis dalam penelitian ini. Dimana dalam penelitian ini, sebagian besar responden memiliki tingkat pendidikan yang rendah. Hal tersebut sesuai dengan penelitian yang dilakukan oleh Merzistya \& Rahayu (2019) yang menyatakan bahwa pasien tuberkulosis dengan pendidikan rendah menunjukkan tingkat kepatuhan yang rendah selama menjalani pengobatan tuberkulosis. Hal tersebut akan mengakibatkan terjadinya kasus resistensi obat tuberkulosis yang semakin meningkat. Selain itu, Padila et al., (2019) menjelaskan hasil analisis bivariat 
dengan uji pearson chi-square menunjukkan nilai p_value $0,000 \leq \alpha 0,005$, artinya ada hubungan signifikan antara pengetahuan dan sikap ibu dengan perawatan ISPA. Penelitian Widyaningtyas et al., (2020) juga menjelaskan dengan pendidikan yang rendah menyebabkan pasien tuberkulosis mengalami kesulitan dalam memahami proses pengobatan tuberkulosis. Hal tersebut mengurangi efikasi pasien tuberkulosis dalam menyelesaikan pengobatan tuberkulosis secara tuntas sesuai dengan waktu yang telah ditentukan oleh pelayanan kesehatan.

Penelitian ini berfokus pada dua variabel penelitian yaitu pengetahuan dan sikap responden tentang pencegahan penularan penyakit tuberkulosis. Berdasarkan hasil pre test, diketahui adanya perbedaan pengetahuan pada kelompok intervensi dengan kelompok kontrol. Rerata pengetahuan responden pada kelompok intervensi sebelum diberikan perlakuan health coaching menunjukkan lebih rendah dibandingkan dengan pengetahuan yang dimiliki oleh kelompok kontrol. Hal tersebut disebabkan karena sebagian besar pekerjaan responden kelompok intervensi merupakan buruh atau pedangan kecil keliling dengan jam kerja yang sangat padat. Sedikitnya kesempatan memanfaatkan pelayanan kesehatan untuk mencari informasi pencegahan tuberkulosis, menyebabkan pasien tuberkulosis menyebabkan rendahnya pengetahuan yang dimiliki oleh responden. Rodriguez et al., (2020) menjelaskan beberapa kategori pekerja yang berisiko mengalami penularan penyakit tuberkulosis memiliki riwayat pendidikan formal yang rendah sehingga mempengaruhi sikap pekerja dalam mencari informasi kesehatan tentang tuberkulosis. Hal tersebut sesuai dengan hal yang diobservasi peneliti dalam pengambilan data, dimana terdapat beberapa kategori pekerjaan responden yang paling berisiko terpapar penularan tuberkulosis diantaranya pekerja di bidang industri mesin dan tekstil.

Faktor lain yang mempengaruhi pengetahuan responden penelitian tentang pencegahan penularan tuberkulosis yaitu kemampuan menggunakan berbagai media yang menyediakan informasi pengobatan dan perawatan tuberkulosis. Sebagian besar hanya memanfaatkan sumber informasi yang berasal dari pusat pelayanan kesehatan terdekat dengan tempat tinggal pasien. Berkaitan dengan hal tersebut, sebagian mengalami hambatan jauhnya akses menuju pelayanan kesehatan tersebut sehingga pengobatan dan upaya pencegahan tuberkulosis tidak maksimal.

Berdasarkan hasil penelitian, responden penelitian sebagian besar masih belum memahami bahwa penyakit tuberkulosis merupakan penyakit yang dapat menular. Sebagian responden penelitian memiliki persepsi bahwa tuberkulosis merupakan penyakit keturunan karena melihat kondisi di keluarga yang mengalami tuberkulosis cukup banyak dari kakek atau nenek, orang tua kemudian anak. Hal tersebut menunjukkan pengetahuan tentang penyakit tuberkulosis masih cukup rendah. Hal tersebut menunjukkan diperlukan upaya yang spesifik sebagai salah satu strategi promosi kesehatan yang dilakukan oleh perawat sehingga pasien tuberkulosis memahami penyakit yang dialaminya dan keluarga. Upaya tersebut diperlukan agar pasien dapat menentukan sikap yang seharusnya dilakukan agar tuberkulosis dapat dicegah. Apabila penyakit tuberkulosis tidak mendapatkan penanganan dengan baik dan manajemen yang sesuai dengan keadaan pasien maka infeksi kronis mycobacterium tuberculosis yang mengakibatkan kerusakan pada paru-paru (Agofure et al., 2018).

Hasil penelitian ini menunjukkan bahwa sikap responden penelitian belum adanya kesadaran dalam melakukan pencegahan penularan tuberkulosis. Hal tersebut dikaitkan dengan pengetahuan yang dimiliki oleh responden penelitian yang masih belum memahami bahaya penyakit tuberkulosis yang dapat menular pada orang lain. Sikap 
yang perlu dievaluasi dari pasien tuberkulosis diantaranya sikap menjaga kebersihan lingkungan yang bebas dari mycobacterium tuberculosis, membuang dahak pada tempat yang tertutup dan menutup mulut dan hidung ketika bersin atau batuk (Dzeyie et al., 2019).

Sikap pencegahan penularan tuberkulosis pada kelompok kontrol ketika pre test menunjukkan nilai yang lebih tinggi. Hal tersebut dikarenakan adanya peran dukungan dari petugas pelayanan kesehatan dalam melakukan homevisit ke rumah pasien. Peranan petugas bersama dengan kader kesehatan dalam proses pengobatan meningkatkan sikap yang positif untuk pasien tuberkulosis. Noé et al., (2017) menjelaskan pasien tuberkulosis perlu diberikan dukungan dalam manajemen pengobatan tuberkulosis. Selain itu, praktik secara langsung diperlukan oleh pasien tuberkulosis sehingga dapat lebih memahami bagaimana sikap yang harus ditunjukkan untuk mencegah penularan penyakit tuberkulosis yang dapat menular pada orang lain.

Peran perawat dalam program tuberkulosis memiliki peranan yang penting sebagai care giver untuk pasien tuberkulosis dan keluarganya. Hal tersebut dikarenakan perawatan tuberkulosis juga memerlukan dukungan dari keluarga. Hasil penelitian ini mendeskripsikan sebagian besar pasien tuberkulosis merupakan pasien yang mengalami pengalaman pertama terdiagnosis penyakit tuberkulosis. Dimana respon dari pasien berbeda-beda karena perbedaan respon dari keluarga yang bervariasi. Beberapa keluarga dengan pengetahuan yang kurang tentang penyakit tuberkulosis kurang mampu memberikan motivasi pada pasien tuberkulosis. Hal tersebut menyebabkan pasien tuberkulosis merasakan tekanan secara moral dan memperburuk manifestasi klinis penyakit tuberkulosis yang dirasakannya. Peranan perawat dalam kondisi tersebut sangat diperlukan untuk memberikan penjelasan pada keluarga dan memotivasi pasien tuberkulosis. Bentuk dukungan dan peranan care giver yang difokuskan dalam penelitian ini menggunakan strategi health coaching.

Pelaksanaan pendidikan kesehatan health coaching dilakukan dengan memberikan bimbingan pada pasien tuberkulosis. Health coaching merupakan suatu intervensi yang diberikan pada pasien tuberkulosis dengan tujuan untuk meningkatkan kemampuan dari pasien tuberkulosis dengan cara interaktif sehingga dapat pasien tuberkulosis dapat memahami cara penularannya. Health coaching juga dapat meningkatkan motivasi pasien tuberkulosis sehingga mempengaruhi keputusan pasien tuberkulosis untuk merubah sikapnya ke arah pencegahan penyakit tuberkulosis. Hal tersebut menstimulasi pasien tuberkulosis untuk meningkatkan kesadaran pasien dan keluarga sesuai dengan kebutuhan dan situasinya masing-masing (Zharfan et al., 2020).

Proses pelaksanaan health coaching yang diberikan pada pasien tuberkulosis dilakukan dengan tahapan yang sistematis. Hubungan saling percaya menjadi salah satu fokus utama perawat. Melalui tahapan tersebut, perawat bersama dengan pasien mengidentifikasi permasalahan yang dialami oleh pasien. Hal tersebut sesuai yang dijelaskan oleh Delaney et al., (2017) bahwa dalam tahapan health coaching yang diberikan pada pasien dengan penyakit kronis diperlukan proses menjalin hubungan face to face agar pasien dan perawat dapat saling percaya dalam menentukan hal-hal yang ingin dicapai dalam membantu mengatasi permasalahan kesehatan yang dialami pasien. Pada proses tersebut, perawat dan pasien juga bersama-sama menentukan metode dalam pelaksaan health coaching sesuai dengan kesepakatan bersama, diantaranya dapat menggunakan media elektronik seperti handphone atau pertemuan langsung. Dalam penelitian ini perawat melakukan health coaching secara langsung dengan melakukan kunjungan ke rumah pasien. Lamanya perawat dan pasien 
melakukan proses health coaching antara 30 sampai 60 menit. Namun, perawat juga menggunakan media komunikasi whatsapp untuk membantu mengontrol pencapaian hasil dan memotivasi pasien dan keluarga.

Pelaksanaan health coaching melalui beberapa tahapan yang dapat dilakukan dengan terstruktur. Tahapan-tahapan dalam health coaching diantaranya menetapkan tujuan dari kemampuan yang ingin dicapai, menetapkan pembimbing dan materi bimbingan, melakukan bimbingan dengan tim kesehatan dan pendukung lainnya, memonitor dan mengevaluasi serta mengukur ketercapaian hasil. Proses health coaching harus selalu dalam bimbingan perawat karena beberapa kendala atau hambatan dapat terjadi pada pasien sehingga perawat dapat membantu dalam pengambilan keputusan yang tepat (Manzi et al., 2017).

Health coaching pada pasien tuberkulosis pada penelitian ini dilakukan dengan melakukan perencanaan pencapaian pengetahuan pencegahan penyakit tuberkulosis yang ingin dicapai oleh pasien. Selain itu pasien juga menentukan sikap pencegahan penularan tuberkulosis yang diharapkan. Kemudian dilakukan monitoring pada pertemuan berikutnya untuk mengevaluasi penerapan pengetahuan atau informasi yang sudah didapatkan dari edukator.

Pengetahuan responden tentang penyakit dan pencegahan penyakit menular pada kelompok intervensi meningkat dengan signifikan. Responden penelitian pada kelompok intervensi menjelaskan bahwa dengan health coaching, responden menjadi lebih memahami perilaku dan hal-hal yang perlu dilakukan untuk mencegah penularan tuberkulosis. Hal ini sejalan dengan penekanan fokus peningkatan pengetahuan tentang tuberkulosis yang dilakukan oleh Adane et al., (2017) dimana pasien tuberkulosis perlu mengetahui penyebab penyakit dan penularan tuberkulosis yang ditularkan melalui droplet atau percikan air ludah. Pasien juga sebaiknya mengetahui tanda dan gejala penyakit tuberkulosis yang mungkin terjadi pada pasien dan keluarganya apabila dirasakan sudah melebihi 2 minggu dan tidak membaik.

Pai et al., (2018) menjelaskan peningkatan pengetahuan pasien tentang pencegahan penularan tuberkulosis sebagai upaya untuk mendukung pengobatan tuberkulosis. Dalam proses pemberian health coaching pada pasien tuberkulosis, penekanan terkait dengan kepatuhan minum obat anti tuberkulosis (OAT), perawat selalu memberikan penekanan. Hal ini dikarenakan beberapa responden penelitian memiliki hambatan dalam mengakses pengobatan tuberkulosis, dimana keluarga kurang memberikan informasi terkait pentingnya ketepatan waktu dalam mengkonsumsi obat tuberkulosis secara rutin. Adanya penurunan gejala tuberkulosis yang dirasakan oleh pasien tuberkulosis menyebabkan pasien merasa sudah sehat dan penurunan motivasi untuk mematuhi aturan pengobatan.

Dukungan keluarga dalam pendampingan pengobatan tuberkulosis dengan jangka yang cukup panjang sangat diperlukan oleh pasien tuberkulosis. Hal ini mengingat banyaknya hal-hal yang khas antara pasien tuberkulosis satu dengan yang lainnya, terutama efek samping dari pengobatan tuberculosis (Nasution et al., 2020). Dukungan keluarga menjadi sumber kekuatan bagi pasien dalam masa pengobatan. Keluarga dapat mengingatkan prosedur pengobatan dan penggunaan terapi lainnya yang mendukung kesehatan pasien. Perawat dapat bekerjasama dengan keluarga untuk meningkatkan motivasi dan kepatuhan pasien selama masa pengobatan (Rotheram-Borus et al., 2018).

Kesadaran pasien dan keluarga bahwa tuberkulosis dapat dicegah sehingga tidak menular kepada orang lain menjadi hasil dari proses bimbingan dari perawat dalam pengobatan tuberkulosis (Samal \& Dehury, 2017). Melalui kesadaran yang semakin 
meningkat, pasien dan keluarga menunjukkan adanya perubahan sikap dalam melakukan hal-hal yang dapat menjadi sarana penularan tuberkulosis. Hal tersebut dapat diketahui dari sikap keluarga dalam upaya pencegahan yaitu menutup mulut dan hidung dengan masker apabila sedang mengalami gejala batuk, memberikan ruangan khusus bagi pasien tuberkulosis dalam beristirahat dan mengkhususkan tempat makan dan minum dari pasien tuberkulosis. Kesadaran keluarga terkait cara mengendalikan sumber infeksi penularan yang dapat menular dari percikan air ludah atau droplet menunjukkan adanya peningkatan pengetahuan pencegahan tuberkulosis dan sinergi dengan petugas pelayanan kesehatan dalam setting keluarga (Dumpeti et al., 2020). Diawasi secara langsung penderita TB dalam mencapai kesembuhannya sangat membutuhkan dukungan dari berbagai pihak terkait (Pratama et al., 2019).

Woimo et al., (2017) menjelaskan bahwa dengan adanya pengetahuan yang baik pasien dapat memotivasi untuk tetap memanfaatkan pelayanan kesehatan walaupun terdapat hambatan-hambatan seperti jarak yang jauh antara rumah dengan pusat pelayanan kesehatan tuberkulosis. Selain itu, dengan adanya kunjungan ke rumah pasien, hal tersebut menunjukkan adanya akses pelayanan kesehatan yang tidak selalu terpusat di salah satu pelayanan kesehatan, sehingga ketika pasien terdapat keluhan terkait dengan gejala tuberkuloisis dapat segera disampaikan kepada perawat. Bimbingan dan edukasi kesehatan yang diberikan melalui kunjungan ke rumah pasien meningkatkan keefektifan manajemen pengobatan tuberkulosis yang berkesinambungan dan komprehensif.

\section{SIMPULAN}

Metode health coaching yang diterapkan pada pasien tuberkulosis menunjukkan adanya pengaruh yang signifikan terhadap peningkatan pengetahuan dan sikap pencegahan penularan tuberkulosis.

\section{SARAN}

Diperlukan dukungan dari masyarakat dan Puskesmas agar intervensi keperawatan pada pasien tuberkulosis dengan memberikan bimbingan dan arahan pada pasien dapat terus dilakukan. Penelitian selanjutnya dapat meneliti lebih spesifik terkait dengan pengaruh health coaching terhadap peningkatan status mental atau kondisi pasien tuberkulosis yang mengalami depresi karena penyakit yang dialaminya.

\section{DAFTAR PUSTAKA}

Adane, K., Spigt, M., Johanna, L., Noortje, D., Abera, S. F., \& Dinant, G. J. (2017). Tuberculosis Knowledge, Attitudes, and Practices among Northern Ethiopian Prisoners: Implications for TB Control Efforts. PLoS One, 12(3). https://doi.org/10.1371/journal.pone.0174692

Agofure, O., Okandeji-Barry, O. R., \& Odjimogho, S. (2018). Knowledge of the Prevention and Management of Tuberculosis among Residents of Bambuka Community Karim-Lamido Local Government Area of Taraba State. SM J Public $\begin{array}{lll}\text { Health } & \text { Epidemiol, } & \text { 4(1), }\end{array}$ https://www.researchgate.net/publication/326753126

Ali, S. M., Kandaou, G. D., \& Kaunang, W. P. . (2019). Faktor - Faktor yang Berhubungan dengan Kepatuhan Berobat Penderita TB Paru di Wilayah Kerja Puskesmas Siko Kota Ternate. Stikes Graha Medika Nursing Journals, 2(1), 1-10. http://journal.stikesgrahamedika.ac.id/index.php/nursing/article/view/69/48 
Andri, J., Febriawati, H., Randi, Y., J, H., \& Setyawati, A. D. (2020). Penatalaksanaan Pengobatan Tuberculosis Paru. Jurnal Kesmas Asclepius, 2(2), 73-80. https://doi.org/10.31539/jka.v2i2.1396

Bojovic, O., Medenica, M., Zivkovic, D., Rakocevic, B., Trajkovic, G., KisicTepavcevic, D., \& Grgurevic, A. (2018). Factors Associated with Patient and Health System Delays in Diagnosis and Treatment of Tuberculosis in Montenegro, 2015-2016. PLoS One, 13(3), e0193997. https://doi.org/10.1371/journal.pone.0193997

Charyeva, Z., Curtis, S., Mullen, S., Senik, T., \& Zaliznyak, O. (2019). What Works Best for Ensuring Treatment Adherence. Lessons from a Social Support Program for People Treated for Tuberculosis in Ukraine. PLoS One, 14(8), e0221688. https://doi.org/10.1371/journal.pone.0221688

Chelagat, T., Kokwaro, G., Onyango, J., \& Rice, J. (2020). Effect of Project-Based Experiential Learning on the Health Service Delivery Indicators: A QuasiExperiment Study. BMC Health Services Research, 20(1), 144. https://doi.org/10.1186/s12913-020-4949-5

Delaney, G., Newlyn, N., Pamplona, E., Hocking, S. L., Glastras, S. J., McGrath, R. T., \& Fulcher, G. R. (2017). Identification of Patients with Diabetes Who Benefit Most from a Health Coaching Program in Chronic Disease Management, Sydney, Australia, 2013. Preventing Chronic Disease, 14(3), E21. https://doi.org/10.5888/pcd14.160504

Dumpeti, S., Jothula, K., \& Naidu, N. (2020). Awareness about Tuberculosis and RNTCP Services among Rural People in Nalgonda District, Telangana. Journal of Family Medicine and Primary Care, 9(7), 3281-3287. https://doi.org/10.4103/jfmpc.jfmpc_415_20

Dzeyie, K., Basu, S., \& Dikid, T. (2019). The Knowledge, Attitude, and Practices Relating to Tuberculosis among Drug-Resistant Tuberculosis Patients. Indian $\begin{array}{llll}\text { Journal of } \quad \text { Medical } & \text { Specialities, }\end{array}$ https://doi.org/10.4103/injms.injms_31_18

Gloria, C. V., Rasyid, Z., W, S. V., Kursani, E., \& Umayyah, B. (2019). Determinan Kepatuhan Minum Obat Pasien Tuberkulosis Paru. Jurnal Kesmas Asclepius, 1(2), 176-185. https://doi.org/10.31539/jka.v1i2.919

Holden, I. K., Lillebaek, T., Andersen, P. H., Wejse, C., \& Johansen, I. S. (2020). Characteristics and Predictors for Tuberculosis Related Mortality in Denmark from 2009 Through 2014: A Retrospective Cohort Study. PLoS One, 15(6). https://doi.org/10.1371/journal.pone.0231821

Inayah, S., \& Wahyono, B. (2019). Penanggulangan Tuberkulosis Paru dengan Strategi DOTS. HIGEIA (Journal of Public Health Research and Development), 3(2), 223-233

Kementrian Kesehatan RI. (2019). Profil Kesehatan Indonesia 2019. In Kementrian Kesehatan RI (Vol. 8, Issue 9)

Kim, S., De Los Reyes V, A. A., \& Jung, E. (2020). Country-Specific Intervention Strategies for Top Three TB Burden Countries Using Mathematical Model. PLoS One, 15(4), e0230964. https://doi.org/10.1371/journal.pone.0230964 
Kwon, M. S., \& Choi, Y. (2020). Factors Affecting Preventive Behavior Related to Tuberculosis among University Students in Korea: Focused on Knowledge, Attitude and Optimistic Bias Related to Tuberculosis. Journal of the Korean Academy of Fundamentals of Nursing, 27(3), 236-245. https://doi.org/10.7739/jkafn.2020.27.3.236

Mamahit, A. Y., Amisi, P. Y., \& Karame, V. (2019). Hubungan Pengetahuan dan Motivasi Penderita Tuberkulosis Paru dengan Kepatuhan Minum Obat. Journal Of Community, 7(1), 1-9. http://ejournal.unpi.ac.id/index.php/JOCE/article/view/140

Manzi, A., Hirschhorn, L. R., Sherr, K., Chirwa, C., Baynes, C., Awoonor-Williams, J. K., Hingora, A., Mboya, D., Exavery, A., Tani, K., Manzi, F., Pemba, S., Phillips, J., Kante, A. M., Ramsey, K., Bawah, A., Nimako, B. A., Kanlisi, N., Jackson, E. F., \& Pio, A. (2017). Mentorship and Coaching to Support Strengthening Healthcare Systems: Lessons Learned Across the Five Population Health Implementation and Training Partnership Projects in Sub-Saharan Africa. BMC Health Services Research, 17(Suppl 3), 831. http://www.embase.com/search/results?subaction=viewrecord \&from=export\&id= L622912972 http://dx.doi.org/10.1186/s12913-017-2656-7

Merzistya, A. N. A., \& Rahayu, S. R. (2019). Kejadian Putus Berobat Penderita Tuberkulosis Paru. Higeia Journal of Public Health Research and Development, 2(3), 298-310. http://journal.unnes.ac.id/sju/index.php/higeia

Nasution, N. S., Andayani, L. S., \& Rochadi, K. R. (2020). The Role of Tuberculosis Cadres in the Tuberculosis Control Program in Medan City. Berita Kedokteran Masyarakat, 36(3), 1-10. https://doi.org/https://doi.org/10.22146/bkm.55207

Ncube, M. (2018). "Posted Home": Migration, Tuberculosis and Structural Violence in Maphisa, Zimbabwe. Anthropology Southern Africa, 41(4), 296-308. https://doi.org/10.1080/23323256.2018.1545591

Noé, A., Ribeiro, R. M., Anselmo, R., Maixenchs, M., Sitole, L., Munguambe, K., Blanco, S., Souef, P., \& García-Basteiro, A. L. (2017). Knowledge, Attitudes and Practices Regarding Tuberculosis Care among Health Workers in Southern Mozambique. BMC Pulmonary Medicine, 17(1), 1-7. https://doi.org/10.1186/s12890-016-0344-8

Padila, P., Febriawati, H., Andri, J., \& Dori, R. A. (2019). Perawatan Infeksi Saluran Pernafasan Akut (Ispa) pada Balita. Jurnal Kesmas Asclepius, 1(1), 25-34. https://doi.org/10.31539/jka.v1i1.526

Pai, M., Delavallade, C., Huddart, S., Bossuroy, T., Pons, V., \& Baral, S. (2018). Knowledge About Tuberculosis and Infection Prevention Behavior: A Nine City Longitudinal Study from India. PLoS One, 13(10), 156. https://doi.org/10.1371/journal.pone.0206245

Parwati, C. G., Farid, M. N., Nasution, H. S., Sulisty., Basri, C., Lolong, D., Gebhard, A., Tiemersma, E. W., Pambudi, I., Surya, A., \& Houben, R. M. G. J. (2020). Estimation of Subnational Tuberculosis Burden: Generation and Application of a New Tool in Indonesia. International Journal of Tuberculosis and Lung Disease, 24(2), 250-257. https://doi.org/10.5588/ijtld.19.0139 
Peña, M. J. M., García, B. S., Baquero-Artigao, F., Pérez, D. M., Pérez, R. P., Echevarría, A. M., Amador, J. T. R., Durán, D. G.-P., \& Julian, A. N. (2018). Tuberculosis Treatment for Children: An Updateactualización Del Tratamiento De La Tuberculosis En Niños. Anales de Pediatría (English Edition), 88(1), 51.e1-e51.e12. https://doi.org/https://doi.org/10.1016/j.anpede.2017.05.001

Pratama, M. Y., Gurning, F. P., \& Suharto, S. (2019). Implementasi Penanggulangan Tuberkulosis di Puskesmas Glugur Darat Kota Medan. Jurnal Kesmas Asclepius, 1(2), 196-205. https://doi.org/10.31539/jka.v1i2.961

Pratama, T. W. Y., Tamtomo, D., \& Sulaeman, E. S. (2018). Factors Associated with the Completeness of Inpatient Medical Record Filling in Dr. R Sosodoro Djatikoesoemo, Bojonegoro, East Java. Journal of Health Policy and Management, 3(1), 1-10. https://doi.org/10.26911/thejhpm.2018.03.01.01

Putri, F. A., Suryawati, C., \& Kusumastuti, W. (2020). Evaluasi Pelaksanaan Program Penanggulangan Tuberkulosis Paru (P2TB) di Puskesmas Bandarharjo Kota Semarang. Jurnal Kesehatan Masyarakat, 8(3), 311-322. https://ejournal3.undip.ac.id/index.php/jkm/article/view/24760/23716

Reid, M. J. A., Arinaminpathy, N., Bloom, A., Bloom, B. R., Boehme, C., Chaisson, R., Chin, D. P., Churchyard, G., Cox, H., Ditiu, L., Dybul, M., Farrar, J., Fauci, A. S., Fekadu, E., Fujiwara, P. I., Hallett, T. B., Hanson, C. L., Harrington, M., Herbert, N., \& Goosby, E. P. (2019). Building a Tuberculosis-Free World: The Lancet Commission on Tuberculosis. In The Lancet (Vol. 393, Issue 10178, pp. 13311384). https://doi.org/10.1016/S0140-6736(19)30024-8

Rodriguez, A., Douphrate, D. I., Gimeno Ruiz De Porras, D., Perez, A., Hagevoort, R., Nonnenmann, M., \& Cienega, L. (2020). Association of Category of Cattle Exposure with Tuberculosis Knowledge among Dairy Workers in Bailey County, Texas. Journal of Agromedicine, 25(1), 1-10. https://doi.org/10.1080/1059924X.2020.1765931

Rotheram-Borus, M. J., Swendeman, D., Rotheram-Fuller, E., \& Youssef, M. K. (2018). Family Coaching as a Delivery Modality for Evidence-Based Prevention Programs. Clinical Child Psychology and Psychiatry, 23(1), 96-109. https://doi.org/10.1177/1359104517721958

Salame, F. M., Ferreira, M. D., Belo, M. T., Teixeira, E. G., Cordeiro-Santos, M., Ximenes, R. A., De Albuquerque, M. D. F. M., Hill, P. C., Menzies, D., \& Trajman, A. (2017). Knowledge about Tuberculosis Transmission and Prevention and Perceptions of Health Service Utilization among Index Cases and Contacts in Brazil: Understanding Losses in the Latent Tuberculosis Cascade of Care. PLoS One, 12(9), e0184061. https://doi.org/10.1371/journal.pone.0184061

Samal, J., \& Dehury, R. K. (2017). Impact of a Structured Tuberculosis Awareness Strategy on the Knowledge and Behaviour of the Families in a Slum Area in Chhattisgarh, India. Journal of Clinical and Diagnostic Research, 11(3), LC11LC15. https://doi.org/10.7860/JCDR/2017/24107.9489

Saunders, M. J., Tovar, M. A., Collier, D., Baldwin, M. R., Montoya, R., Valencia, T. R., Gilman, R. H., \& Evans, C. A. (2019). Active and Passive Case-Finding in Tuberculosis-Affected Households in Peru: A 10-Year Prospective Cohort Study. The Lancet Infectious Diseases, 19(5), 519-528. https://doi.org/10.1016/S14733099(18)30753-9 
Singh, H., Kennedy, G. A., \& Stupans, I. (2020). Does the Modality Used in Health Coaching Matter? A Systematic Review of Health Coaching Outcomes. In Patient Preference and Adherence (Vol. 14, pp. 1477-1492). https://doi.org/10.2147/PPA.S265958

Smiljić, S., Radović, B., Ilić, A., Trajković, G., Savić, S., Milanović, Z., \& Mijović, M. (2019). Differences and Similarities Between the Symptoms and Clinical Signs in Patients With Pulmonary Tuberculosis And Pneumonia. Vojnosanitetski Pregled, 76(2), 192-201. https://doi.org/10.2298/VSP170301080S

WHO. (2019). Tuberculosis Global Report 2019. In World Health Organization. https://www.who.int/tb/publications/global_report/en/

Widiyanto, A. (2017). Hubungan Kepatuhan Minum Obat dengan Kesembuhan Pasien Tuberkulosis Paru BTA Positif di Puskesmas Delanggu Kabupaten Klaten. Interest: Jurnal Ilmu Kesehatan, 6(1), 7-12. https://doi.org/10.37341/interest.v6i1.71

Widyaningtyas, P., Candrasari, A., Jatmiko, S. W., \& Lestari, N. (2020). Efikasi Diri Dan Tingkat Pendidikan Mempengaruhi Kepatuhan Pengobatan Pasien Tuberkulosis. Proceeding, 256-260. http://repository.urecol.org/index.php/proceeding/article/view/1075

Woimo, T. T., Yimer, W. K., Bati, T., \& Gesesew, H. A. (2017). The Prevalence and Factors Associated for Anti-Tuberculosis Treatment Non-Adherence among Pulmonary Tuberculosis Patients in Public Health Care Facilities in South Ethiopia: A Cross-Sectional Study. BMC Public Health, 17(1), 269. https://doi.org/10.1186/s12889-017-4188-9

Zharfan, H. D., Amin, M., \& Setiya, W. A. (2020). The Effect of Health CoachingBased Health Belief Model on Preventing the Pulmonary Tuberculosis Transmission at Puskesmas Karang Taliwang and Ampenan West Nusa Tenggara. International Journal of Nursing and Health Services (IJNHS), 3(4), 494-500. http://ijnhs.net/index.php/ijnhs/homehttp://doi.org.10.35654/ijnhs.v3i4.253 